\title{
BNWL-380
}

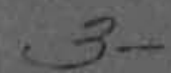

\section{THE EFFECT OF IMPREGNATION AND CRYSTALITE ORIENTATION ON THE RADIATION INDUCED CONTRACTION OF GRAPHITE}

DEVELOPMENT

BEPORT

J. H. COX, JR.

JULY, 1967

DUN for 6000023001304961

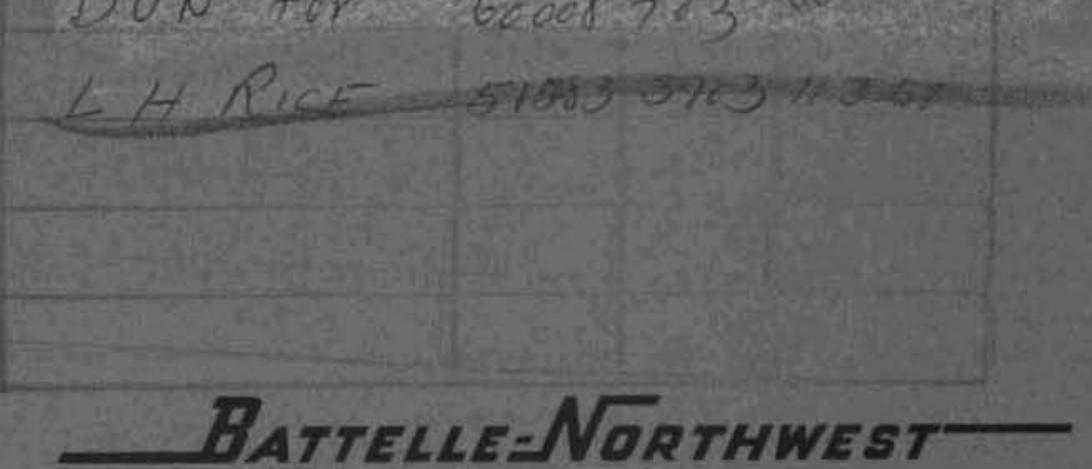

BATTELLE MEMORIAL INSTITUTE / PACIFIC NORTHWEST LABORATORY 


\section{LEGAL NOTICE}

This report was prepared as an account of Government sponsored work. Neither the Unifed States, nor the Commission, nor any person acting on beholf of the Commission:

A. Makes any warranty or representation, expressed or implied, with respect to the accuracy, completeness, or usefulness of the information contained in this report, or that the use of any information, apparatus, method, or process disclosed in this report may not infringe privately owned rights; or

B. Assumes any liabilities with respect to the use of, or for damages resulting from the use of any information, apparatus, method, or process disclosed in this report.

As used in the above, "person acting on behalf of the Commission" includes any employee or contractor of the Commission, or employee of such contractor, to the extent that such employee or contractor of the Commission, or employee of such contractor prepares, disseminates, or provides access to. any information pursuant to his employment or contract with the Commission, or his employment with such contractor:

\section{PACIFIC NORTHWEST LABORATORY \\ RICHLAND, WASHINGTON \\ operaled by}

BATTELLE MEMORIAL. INSTITUTE

for the

UNITED STATES ATOMIC ENERGY COMMISSION UNDER CONTRACT AT(45-1)-1830 
BMWL -380

\section{ERRATA}

There is an error in the equation on page 6. It was typed

$$
\frac{1}{l_{x}} \frac{d_{\ell x}}{d \gamma}=A+B a_{x}
$$

The correct equation should be written as follows:

$$
\frac{1}{\ell_{x}} \frac{d l_{x}}{d \gamma}=A+B a_{x}
$$




\title{
33679000605396
}

\author{
BNWL - 380 \\ UC-25, Metals, Ceramics, \\ and Materials
}

\section{THE EFFECT OF IMPREGNATION AND CRYSTALLITE \\ ORIENTATION ON THE RADIATION INDUCED CONTRACTION OF GRAPHITE ${ }^{(1)}$}

By

J. H. Cox, Jr.

Ceramics and Graphite Research Section Materials Department

July, 1967

\section{PACIFIC NORTHWEST LABORATORY RICHLAND, WASHINGTON}

(1) This report consists of portions of a thesis presented by the author at the University of Washington in partial fulfizzment of the requirements for the degree of Master of Science in Engineering. 
Printed in the United States of America Available from

Clearinghouse for Federal Scientific and Technical Information National Bureau of Standards, U.S. Department of Commerce Springfield, Virginia 22151

Price: Printed Copy $\$ 3.00 ;$ Microfiche $\$ 0.65$ 


\title{
THE EFFECT OF IMPREGNATION AND CRYSTALLITE ORIENTATION ON THE RADIATION INDUCED CONTRACTION OF GRAPHITE
}

\author{
J. H. Cox, Jr.
}

\begin{abstract}
$\underline{\text { ABSTRACT }}$
This study has been concerned with the effects of crystallite orientation and impregnant level on radiation-induced bulk contraction in polycrystalline graphite. Radiations reached a maximum exposure of $1.3 \times 10^{21} \mathrm{nvt}(\mathrm{E}>0.18 \mathrm{MeV}$ ) in a temperature range of 500 to $700{ }^{\circ} \mathrm{C}$. The description of graphite as a single-phase material effected a correlation between crystallite orientation and dimensional changes in a series of samples that were identical except for the degree of anisotropy. However, increasing the impregnant level increased the dimensional changes and showed that the single-phase description was inadequate as a completely general method of characterizing the radiation behavior of graphite.
\end{abstract}


TABLE OF CONTENTS

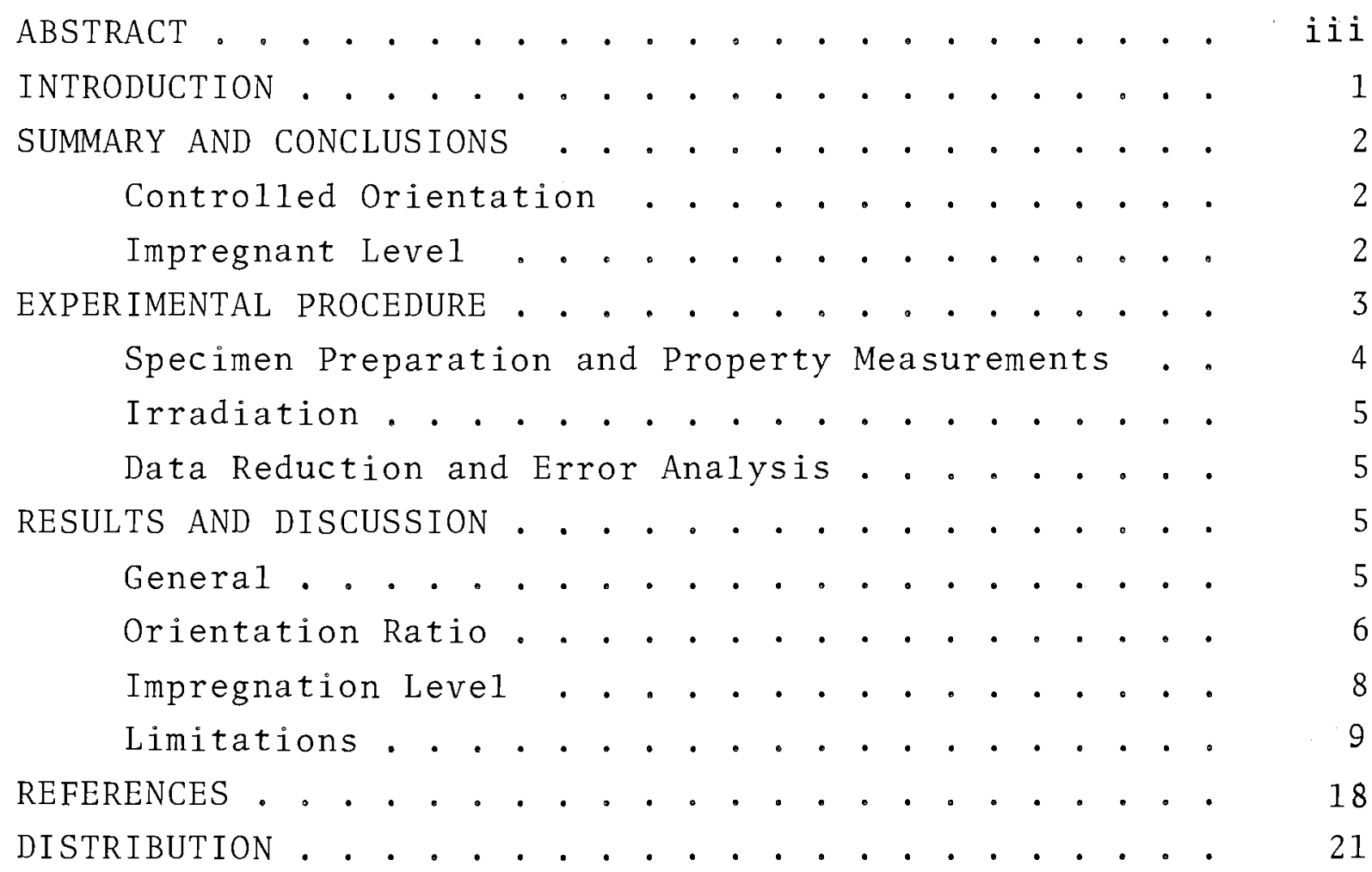




\section{THE EFFECT OF IMPREGNATION AND CRYSTALLITE \\ ORIENTATION ON THE RADIATION INDUCED \\ CONTRACTION OF GRAPHITE}

J. H. Cox, Jr.

\section{INTRODUCTION}

This study evaluates the applicability or validity of the various models of radiation-induced contraction in graphite. By determining the applicability of the various models, the study would define the range of interpolation or extrapolation permitted in each case. Such experimental tests also help determine the validity of the structure assumed for graphite in developing the theoretical models.

Two schools of thought depict the dimensional stability in graphite. The first (Simmon's model) (1) asserts a direct relationship between the contraction rate of graphite and the contraction rates of individual crystallites. An accommodation factor has been proposed which depends upon the type of graphite, the degree of preferred orientation of crystallites, and the irradiation dose and temperature. By means of this factor, the dimensional stability may be related to the coefficient of thermal expansion. To test this mode1, one series of samples was prepared allowing the value of the coefficient of thermal expansion (CTE) to vary throughout as large a range as possible $\left(0.49\right.$ to $\left.3.03 \times 10^{-6} /{ }^{\circ} \mathrm{C} 25-125^{\circ} \mathrm{C}\right)$ while holding the other processing variables to constant measurements. The second persuasion (2) attributes contraction to two separable processes, one related to the binder phase of the graphite and the other related to the crystallites. This model was tested by a series of samples made from the same base graphite, but using leve1s of nongraphitizing impregnant which varied from 1 to $21 \mathrm{wt} \%$. 
Property measurements included the aggregate length and coefficient of thermal expansion. The samples were irradiated in the Hanford hot test holes. Total exposures were to 1.33 $x 10^{21} \mathrm{nvt}(\mathrm{E}>0.18 \mathrm{MeV}) *$ and the irradiation temperatures were $600{ }^{\circ} \mathrm{C} \pm 100^{\circ} \mathrm{C}$.

\section{SUMMARY AND CONCLUSIONS}

CONTROLLED ORIENTATION

In a series of samples identical except in the relative orientation of the crystallites within the graphite matrix, one may predict contraction rates under neutron irradiation for different orientations based on contraction rate data for any one orientation. Although the calculated single-crystal dimensional changes are less than those found in pyrolytic graphite, these data are consistent with a single-phase model. As a result the single-phase model may be used effectively to predict contraction rates of very similar nuclear graphites at exposures below "turnaround," providing radiation data on one graphite are available.

\section{IMPREGNANT LEVEL}

The impregnant level has a definite effect on the contraction rate of graphite under neutron irradiation. At higher impregnant levels, approximately $16 \%$ for the graphite studied in this work, the contraction rate increased with the impregnant level. A plausible explanation is that at low impregnant levels the open pore volume is preferentially filled, and there is no effect on the dimensional behavior of the bulk. However, as the open pores are filled and the binder assumes part of the supporting structure, there is an increased contraction rate due to the binder contracting at a more rapid rate than the filler, These observations support a two-phase model.

* Alr exposures presented are $(E>0.18 \mathrm{MeV}) .(3-4)$ 
The actual mechanism of contraction must involve more than a single phase. To predict dimensional behavior over the wide spectrum of manufactured graphites, a quantitative method must be found for the application of a multiple phase model.

\section{EXPERIMENTAL PROCEDURE}

The first sample series incorporated a wide range of coefficients of thermal expansion in materials that were processed identically except for the forming step. This series was designed to test the validity of the single-phase model. If the Simmons model is valid, the single-phase equations should predict identical crystal contraction rates for this entire sample series.

This series of controlled-orientation samples(5) was made by either molding, extruding, or a combination of both. The green mix, consisting of Continental coke flour having a maximum particle size of 0.016 in. and 30 medium pitch as binder, was extruded as 5-1/8 in. diameter rounds and cut into short lengths. The green stock was reformed by molding with the force applied parallel to the extrusion axis. The molding pressure was adjusted to yield plugs with a graded reversal of the orientation induced by the initial extrusion. A final set was molded as $6-1 / 8$ in. diameter rounds directly from the green mix. The stock was then graphitized at $3000^{\circ} \mathrm{C}$; the quantity of binder carbon was determined to be $16 \%$ of the total carbon present.

The orientation ratios, as determined by the transverseto-longitudinal coefficient of thermal expansion, were 6.18 , 2.39 , and 0.78 . Although some nearly isotropic graphites were formed, the low-expansion characteristics of Continental coke dominated the volume expansion, which remained low.

The second sample series, comprised of materials identical except for binder or impregnant level, was designed to test the 
BNWL - 380

two-phase mode1. On the basis of the two-phase model one would expect the contraction rate to increase with increasing binder level.

The impregnation-level series of samples (5) was made from base stock of a mix of Continental coke filler and 30 medium coal-tar pitch binder extruded with a 4-1/2 x 4-1/2 in. cross section. The binder-carbon content varied from 10.5 to $12 \%$. The formed bars were impregnated with both coal-tar pitch and thermosetting resin to various levels, as shown in Table I. After impregnation, the samples were graphitized at $3000{ }^{\circ} \mathrm{C}$.

The processing of the second series increased the amount of less-graphitic carbon in the selected filler system so that irradiation effects originating in the nongraphitic portions could be more easily perceived. The most convenient method by which carbon may be added to a particular filler system is by impregnating previously formed graphite with either pitch or resins and then coking the impregnant. This procedure allows one to hold other properties more constant than is possible by a method which varies the initial binder level. In addition to being the most practical approach, impregnation permits the evaluation of pitch cokes versus thermosetting resin cokes which are cross-1inking and nongraphitizing.

\section{SPECIMEN PREPARATION AND PROPERTY MEASUREMENTS}

The samples were machined to 0.426 in. diameter by 4 -in. long cylinders, and the rounded ends were polished. Stresses introduced into the samples by the machining can cause small dimensional changes during annealing. Because such stress can influence the length measurements after low-exposure at high temperature, all samples were annealed at $1000^{\circ} \mathrm{C}$ after machining.

Property measurements included length and coefficient of thermal expansion. Lengths were measured with a Baush and Lomb DR-25 Optical Gage (Type 33-14-23). The length measurements had 
a standard deviation of $2 \times 10^{-5}$ in. Coefficient of therma 1 expansion values were determined from 25 to $100{ }^{\circ} \mathrm{C}$ using a quartz drive and a Starrett gage (No。656-611), a11owing a standard deviation of approximately $5 \times 10^{-2}$ in./in. ${ }^{\circ} \mathrm{C}$.

IRRADI AT ION

The samples were irradiated in the Hanford reactor hot test holes. During irradiation they were contained in hollow graphite bars equipped with sliding covers. The irradiation temperature varied from 550 to $700{ }^{\circ} \mathrm{C}$, as determined previously. The capsule atmosphere, identical for all samples, consisted of a mixture of helium and carbon dioxide.

The incident neutron flux was measured with nickel, iron, and cobalt flux monitor wires. Integral cross sections for the fast neutron monitors were determined from the cross sections for the materials and the calculated neutron spectra for the irradiation facility. The experimental details for determining the neutron exposures are discussed by Morgan (6) in the description of the computer code (foils) used. Al1 wire counting was done with the gamma analytical system (7) at Hanford. DATA REDUCTION AND ERROR ANALYSIS

The variation of length measurements on an individual sample was $2 \times 10^{-5}$ in., which was low enough to ignore in the data analysis. The average length change, and the standard deviation for each group of samples at each exposure was calculated. A least-squares fit of the sample groups then gave a contraction rate over the complete set.

\section{RESULTS AND DISCUSSION}

\section{GENERAL}

Data for the controlled-orientation series are given in Table II, and data for the impregnation series are given in Table I. Al1 data, by sample sets, were correlated by the 
least-squares method, and Figure 1 shows the results for the controlled-orientation series. The data for the impregnant-level series were also correlated by the least-squares method before contraction rates were determined.

ORIENTATION RATIO

For the Simmons' equations to be valid, the growth rate should be a linear function of the coefficient of thermal expansion for the aggregate, as implied by the equation below,

$$
\frac{1}{\ell_{x}} \frac{d x}{d y}=A+B \alpha_{x}
$$

For this series the single-crystal growth per unit dose should be constant since all samples contain the same coke and binder, and have the same processing temperature history. Hence, the first test of the data was to plot the coefficient of thermal expansion versus the contraction rate, as shown in Figure 2 ; the relationship is 1 inear within experimental error.

An alternative analysis of the data consists of solving the Simmons' equations for single-crystal dimensional changes, knowing the crystal coefficient of thermal expansion, the aggregate coefficient of thermal expansion, and the rate of dimensional change with exposure. Thus, by using the coefficients and contraction rates given in Table II, the single-crystal coefficients given by Nelson and Riley, (8)

$$
\begin{aligned}
& \alpha_{\mathrm{c}}=27.2 \times 10^{-6} /{ }^{\circ} \mathrm{C}\left(25-100^{\circ} \mathrm{C}\right) \\
& \alpha_{\mathrm{a}}=-1.3 \times 10^{-6} /{ }^{\circ} \mathrm{C}\left(25-100^{\circ} \mathrm{C}\right)
\end{aligned}
$$

and the Simmons' equations,

$$
\alpha_{x}=A_{x} \alpha_{c}+\left(1-A_{x}\right) \alpha_{a}
$$




$$
\frac{1}{\ell_{x}} \frac{d \ell_{x}}{d \gamma}=A_{x} \frac{1}{x_{c}} \frac{d x_{c}}{d \gamma}+\left(1-A_{x}\right) \frac{1}{x_{a}} \frac{d x}{d y}
$$

the accommodation factor $A_{x}$ may be found for each aggregate coefficient. Knowing the accommodation factor and the bulk growth rate, one may find the single-crystal growth rates. The growth rates were determined as $-0.167 \pm 0.007 \frac{\% \Delta L}{\mathrm{~L}} / 10^{21} \mathrm{nvt}$ for the a-axis and $+0.390 \pm 0.014 \frac{\frac{0}{L} \Delta L}{L} / 10^{21}$ nvt for the $\underline{c}$-axis.

The available irradiation data for pyrolytic graphite do not yield growth rates in agreement with these calculated rates. Limited irradiation data are available for pyrolytic material graphitized at two temperatures. Data obtained by the author ${ }^{(9)}$ based on the continuation ( $n v t=1.5 \times 10^{21}$ ) of irradiation studies initiated by Yoshikawa ${ }^{(10)}$ on pyrolytic material graphitized at $2200^{\circ} \mathrm{C}$, yielded growth rates of +2.01 and $-0.80 \% / 10^{21}$ nvt for the $\underline{c}$ and $a$ axis, respectively. For pyrolytic graphite processed at $2900^{\circ} \mathrm{C}$, Kelley et a1. (11) reported growth rates of +1.01 and $-0.37 \% / 10^{21} \mathrm{nvt}$ for the $\underline{c}$ and a axis, respectively, at exposures to $2.14 \times 10^{21} \mathrm{nvt}$.

The calculated single-crystal dimensional changes, based on the present work, are much lower than those based on pyrolytic data. However, one might expect different apparent singlecrystal changes over a range of processing temperatures or varying degrees of graphitization of the material. That is to say, as the material becomes more graphitic due to an increased processing temperature, one would expect a lower apparent crystal contraction rate because ordering in the bulk graphite improves dimensional stability. This effect of ordering can be seen in a sample series currently being studied. A Texas coke series was graphitized at various levels from 1300 to $2700^{\circ} \mathrm{C}$. The coefficient of thermal expansion did not change with temperature; however, the degree of graphitization, as determined by crystallite 
size and layer spacing, increased with increasing graphitization temperature. Moreover, the contraction rates, as shown in Figure 3 , decreased with increasing graphitization temperature.

Therefore, one cannot condemn the single-phase model because contraction rates, based on pyrolytic data used for single-crystal dimensional changes, do not agree with experimental values for polycrystalline graphite. It would appear, rather, that the dimensional changes are dependent upon the degree of perfection within the crystal and, therefore, must be determined for each specific type of material.

\section{IMPREGNATION LEVEL}

The impregnation-level series may be approached in either of two ways--a consideration of the dimensional stability relative to either the impregnant level or to the impregnant plus binder leve1. The binder level for all samples, as 1 isted in Table I, is about $12 \mathrm{wt}$. Therefore, to consider the binder plus impregnant does not change the nature of the curve but only shifts the origin of the curves. The data from Tables I and III, for the contraction rate relative to the impregnant level, are presented in Figures 4 and 5 for the transverse and parallel samples respectively. Note that there is a definite effect of the impregnant at the higher impregnant levels, above $16 \%$, approximately.

The thermal-expansion values 1 isted in Table III are essentially constant over the whole spectrum of impregnant levels. Hence, it is obvious that the single-phase relationships do not hold over a variable binder level.

One explanation for this behavior is the preferential filling of open pores until the binder becomes part of the supporting structure. An open-pore value of $216 \%$ is assumed. Previous investigations $(12,13)$ indicate that this is a reasonable number. Up to an impregnant level of $16 \%$ there is no effect, because the 
impregnant is filling the open pores and shrinking away during graphitization. However, as the impregnant level approaches the open pore volume, the impregnant becomes part of the supporting structure after going through the graphitization step in processing. As a result, the dimensional behavior of the bulk under neutron irradiation is determined not only by the behavior of the filler material, but also by the behavior of the binder and impregnant material. As the impregnant level is raised, it contributes more to the bulk behavior.

The changes postulated above are not indicated by coefficient of thermal expansion values. Price and Bokros (14) predict that a random aggregate would have a coefficient of thermal expansion approximately equal to that of the transverse orientation for the singly impregnated graphites. As a result, any change in the coefficient due to the added impregnant, which is assumed to be random, would be very small. From the coefficients listed in Table III, it can be seen that the parallel values increase slightly with the added impregnant while the transverse samples show no change.

\section{LIMITATIONS}

The exposure range of this experiment is limited to the contraction portion of the dimensional-change curve for graphite. As a result, the higher-exposure range, where the transverse orientation shows "turnaround," $(15,16)$ or a rapid growth rate, is not considered. 


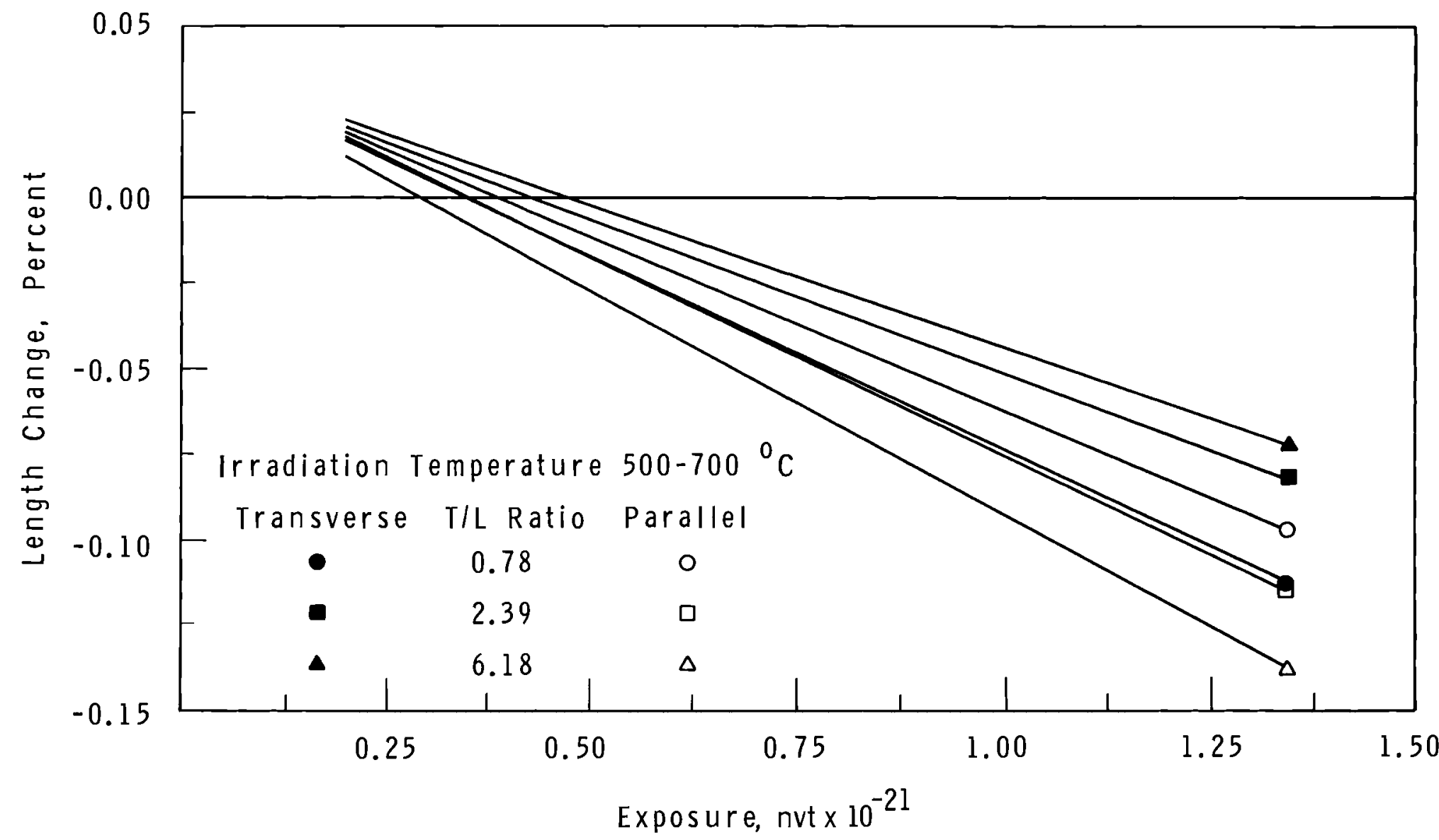

FIGURE 1. Radiation Induced Length Changes Controlled orientation Series (Least Squares Fit) 


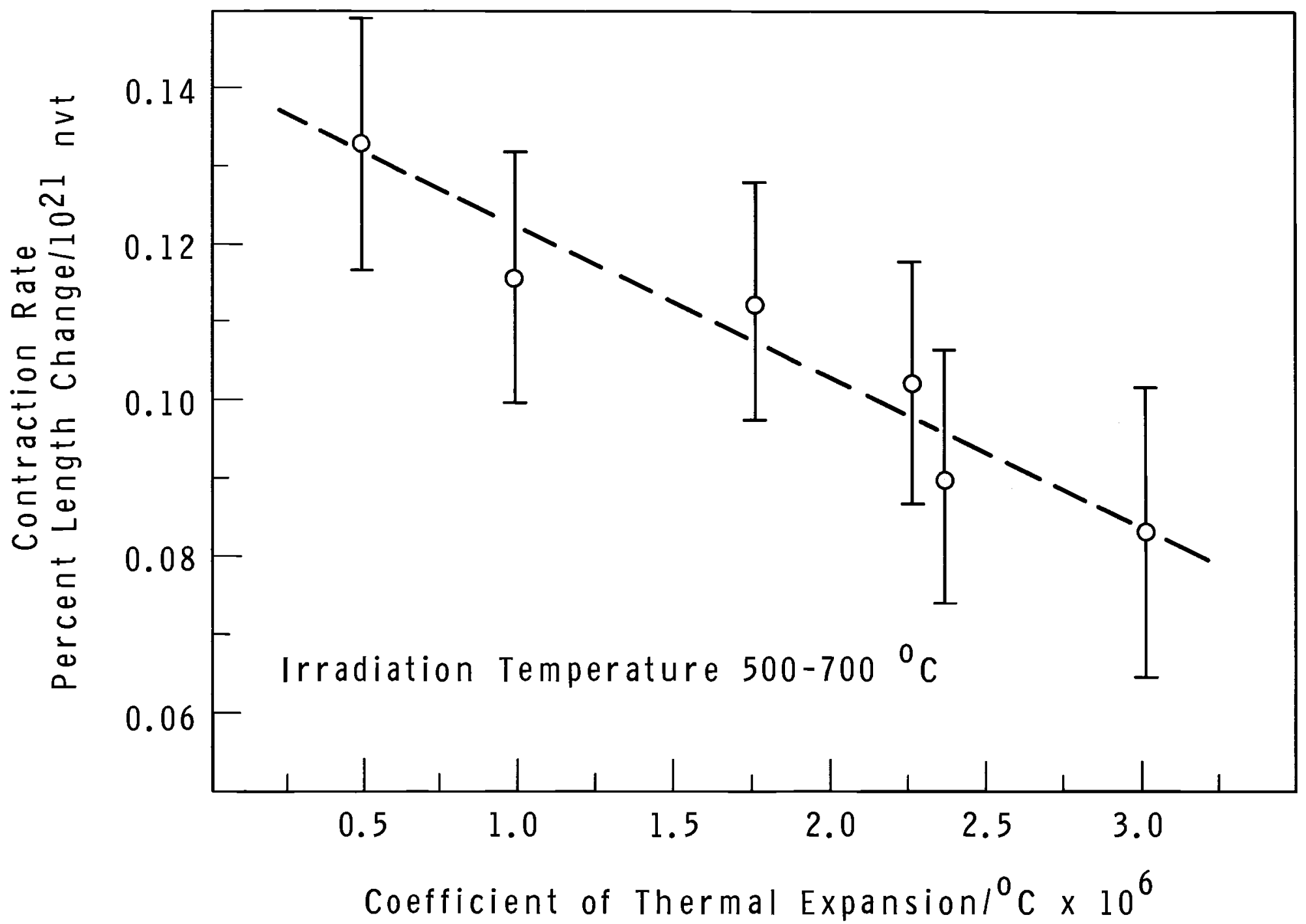

FIGURE 2. Controlzed Orientation Series Coefficient of Thermal Expansion Versus Radiation Induced Contraction Rate 


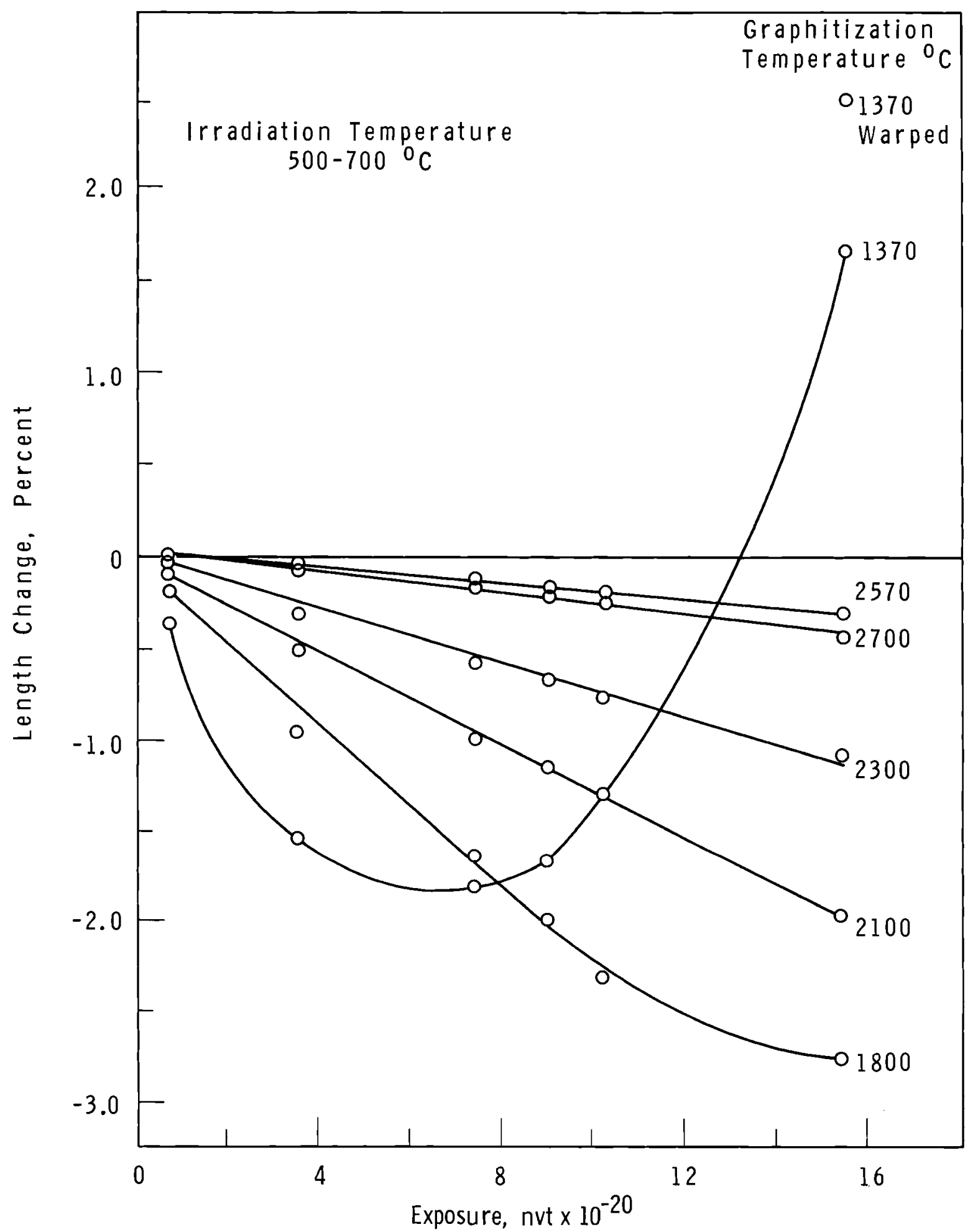

Figure 3. Temperature of Graphitization Series Radiation Induced Length Changes (Transverse orientation) 


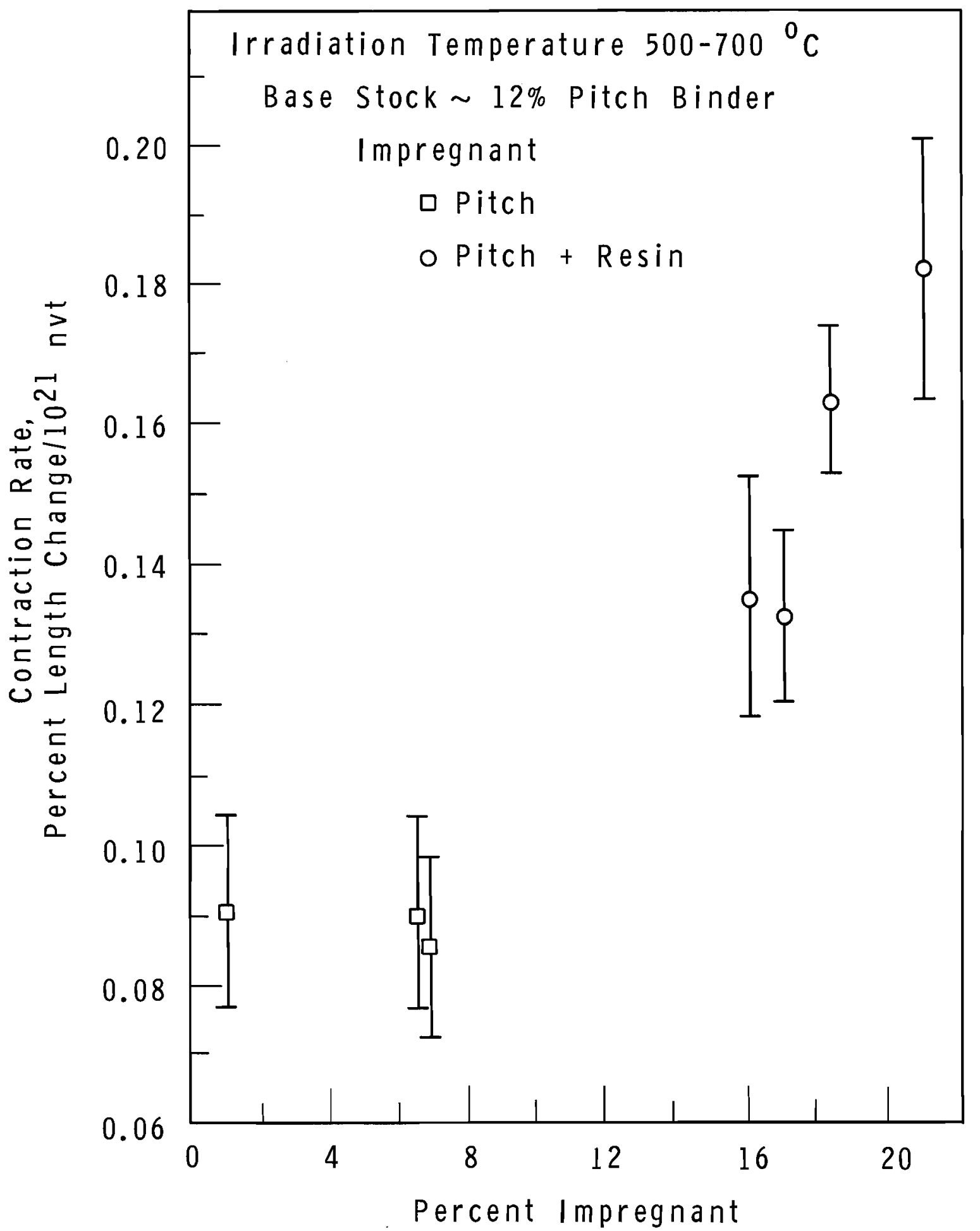

FIGURE 4. Impregnant Level Series Radiation Induced Contraction Rate Versus Percent Impregnant (Transverse orientation) 


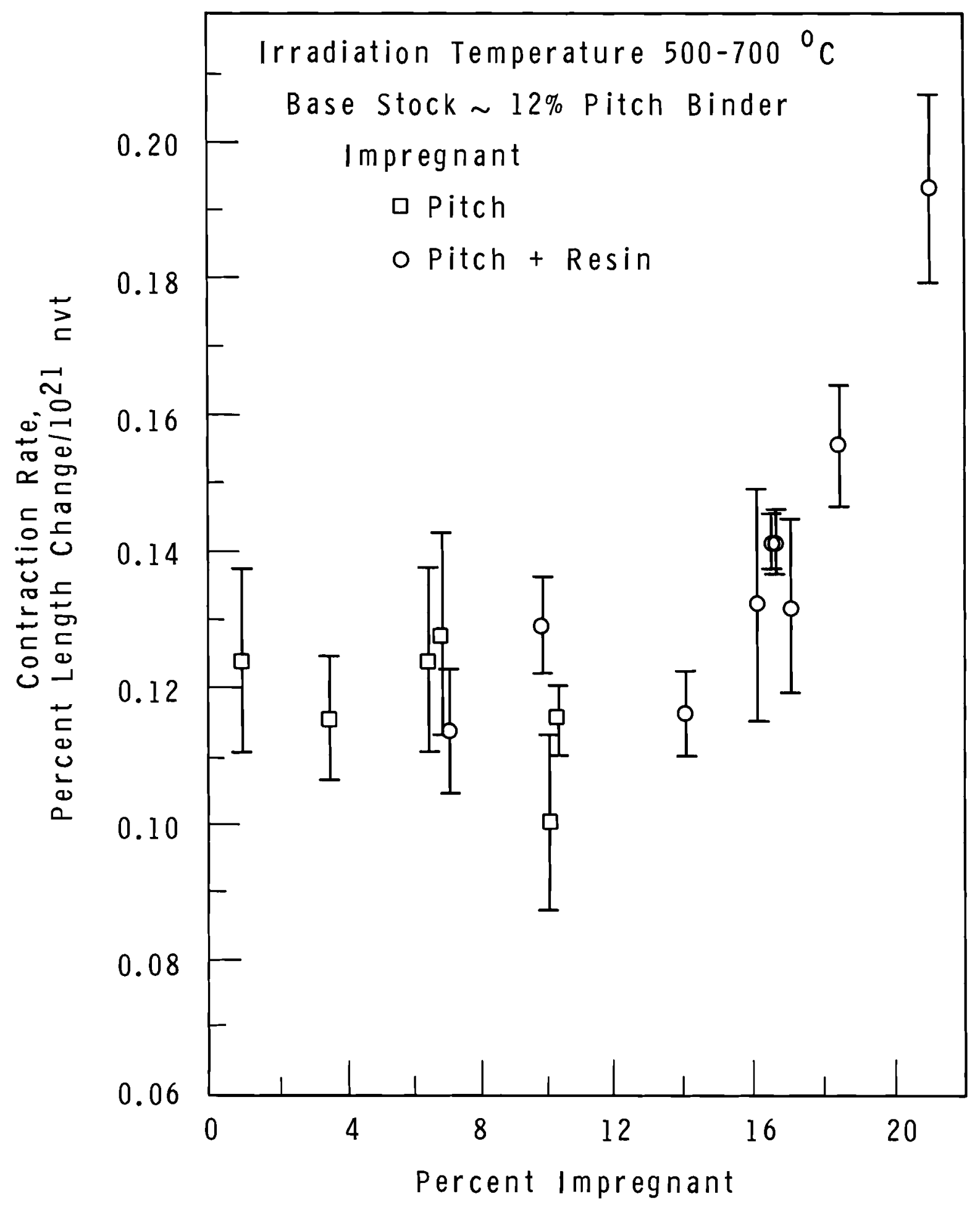

FIGURE 5. Impregnant Level Series Radiation Induced Contraction Rate Versus Percent Impregnant (Parallel orientation) 
TABLE I. Impregnation Level Series

Impregnant Levels

\begin{tabular}{|c|c|c|c|c|c|c|c|}
\hline \multirow[b]{3}{*}{ Sample Set } & \multicolumn{6}{|c|}{ Binder and Impregnant (percent) } & \multirow{3}{*}{$\begin{array}{l}\text { Apparent } \\
\text { Density } \\
\text { (g/cc) }\end{array}$} \\
\hline & \multicolumn{3}{|c|}{ Coal-Tar Pitch } & \multirow{2}{*}{$\begin{array}{c}\text { Resin } \\
\text { Impregnant }\end{array}$} & \multicolumn{2}{|c|}{ Total } & \\
\hline & Binder & Impregnant & Total & & Impregnant & $\begin{array}{l}\text { Binder and } \\
\text { Impregnant }\end{array}$ & \\
\hline 60 & 10.5 & 1.0 & 11.5 & ---- & 1.0 & 11.5 & 1.55 \\
\hline 30 & 11.2 & 6.8 & 18.0 & ---- & 6.8 & 18.0 & 1.54 \\
\hline 15 & 12.0 & 6.5 & 18.5 & ---- & 6.5 & 18.5 & 1.59 \\
\hline $\mathrm{C}-1$ to 10 & 10.5 & $3.5(2)^{1}$ & 14.0 & ---- & 3.5 & 14.0 & 1.64 \\
\hline$B-1$ to 10 & 11.2 & $10.3(2)$ & 21.3 & ---- & 10.3 & 21.3 & 1.63 \\
\hline A-1 to 10 & 12.0 & $10.2(2)$ & 22.2 & ---- & 10.2 & 22.2 & 1.66 \\
\hline $\mathrm{C}-11$ to 20 & 10.5 & 1.0 & 11.5 & 6.0 & 7.0 & 17.0 & 1.69 \\
\hline A-11 to 20 & 12.0 & 6.5 & 18.5 & 7.5 & 14.0 & 26.0 & 1.73 \\
\hline$C-21$ to 30 & 10.5 & 1.0 & 11.5 & $8.8(2)$ & 9.8 & 19.8 & 1.74 \\
\hline B-21 to 30 & 11.2 & 6.8 & 18.0 & 9.6 (2) & 16.4 & 27.6 & 1.74 \\
\hline A-21 to 30 & 12.0 & 6.5 & 18.5 & $10.0(2)$ & 16.5 & 28.5 & 1.78 \\
\hline I-1 & 12.0 & 6.5 & 18.5 & 11.8 & 18.3 & 30.3 & 1.78 \\
\hline $\mid-2$ & 12.0 & 6.5 & 18.5 & 9.5 & 16.0 & 28.0 & 1.79 \\
\hline $1-3$ & 12.0 & 6.5 & 18.5 & $14.5(2)$ & 21.0 & 33.0 & 1.80 \\
\hline $1-4$ & 12.0 & 6.5 & 18.5 & 11.0 (2) & 17.0 & 29.0 & 1.81 \\
\hline
\end{tabular}

${ }^{1}$ Designates the Number of Impregnation Steps 
TABLE II. Controlled Orientation Series Contraction Rates

\begin{tabular}{|c|c|c|c|c|}
\hline $\begin{array}{c}\text { Sample Set } \\
\text { T/L Ratio } \\
\end{array}$ & Orientation & $\begin{array}{c}\text { Initial } \\
\text { CTE } \times 10^{6} \\
\left(25-100^{\circ} \mathrm{C}\right) \\
\end{array}$ & $\begin{array}{c}\text { Contraction Rate } \\
\text { \% Length Changel } \\
\left.10^{21} \text { nvt (E }>0.18 \mathrm{MeV}\right) \\
\left(0.2 \text { to } 1.3 \times 10^{21} \mathrm{nvt}\right) \\
\end{array}$ & $\begin{array}{l}\text { Standard } \\
\text { Deviation }\end{array}$ \\
\hline 6.18 & Transverse & 3.03 & 0.0832 & \pm 0.0185 \\
\hline 2.39 & Transverse & 2.37 & 0.0896 & \pm 0.0168 \\
\hline 0.78 & Parallel & 2.26 & 0.1020 & \pm 0.0156 \\
\hline 0.78 & Transverse & 1.76 & 0.1125 & \pm 0.0154 \\
\hline 2.39 & Parallel & 0.99 & 0.1156 & \pm 0.0161 \\
\hline 6.18 & Parallel & 0.49 & 0.1328 & \pm 0.0164 \\
\hline
\end{tabular}


TABLE III. Impregnation Level Series Contraction Rates

\begin{tabular}{|c|c|c|c|c|}
\hline Sample Set & Orientation & $\begin{array}{c}\text { Initial } \\
\text { CTE x 1 } 10^{6} \\
\left(25-1000^{\circ} \mathrm{C}\right) \\
\end{array}$ & $\begin{array}{c}\text { Contraction Rate } \\
\text { \% Length Changel } \\
\left.10^{21} \text { nvt (E }>0.18 \mathrm{MeV}\right) \\
\left(0.2 \text { to } 1.3 \times 10^{21} \mathrm{nvt}\right) \\
\end{array}$ & $\begin{array}{l}\text { Standard } \\
\text { Deviation } \\
\end{array}$ \\
\hline \multirow[t]{2}{*}{60} & Transverse & 2.05 & 0.091 & \pm 0.014 \\
\hline & Parallel & 0.54 & 0.124 & \pm 0.013 \\
\hline \multirow[t]{2}{*}{30} & Transverse & 2.25 & 0.086 & \pm 0.013 \\
\hline & Parallel & 0.65 & 0.128 & \pm 0.015 \\
\hline \multirow[t]{2}{*}{15} & Transverse & 2.54 & 0.091 & \pm 0.014 \\
\hline & Parallel & 0.44 & 0.124 & \pm 0.013 \\
\hline C-1 to 10 & Parallel & ---- & 0.116 & \pm 0.009 \\
\hline B-1 to 10 & Parallel & ---- & 0.116 & \pm 0.005 \\
\hline$A-1$ to 10 & Parallel & ---- & 0.101 & \pm 0.013 \\
\hline C-11 to 20 & Parallel & ---- & 0.114 & \pm 0.009 \\
\hline A-11 to 20 & Parallel & ---- & 0.117 & \pm 0.006 \\
\hline $0-21$ to 30 & Parallel & ---- & 0.130 & \pm 0.007 \\
\hline$B-21$ to 30 & Parallel & ---- & 0.142 & \pm 0.004 \\
\hline$A-21$ to 30 & Parallel & ---- & 0.142 & \pm 0.005 \\
\hline \multirow[t]{2}{*}{$\mid-1$} & Transverse & 2.13 & 0.164 & \pm 0.011 \\
\hline & Parallel & 0.86 & 0.156 & \pm 0.009 \\
\hline \multirow[t]{2}{*}{$1-2$} & Transverse & 2.13 & 0.136 & \pm 0.017 \\
\hline & Parallel & 0.78 & 0.133 & \pm 0.017 \\
\hline \multirow[t]{2}{*}{$1-3$} & Transverse & 2.23 & 0.183 & \pm 0.019 \\
\hline & Parallel & 0.82 & 0.194 & \pm 0.014 \\
\hline \multirow[t]{2}{*}{$1-4$} & Transverse & 2.36 & 0.133 & \pm 0.012 \\
\hline & Parallel & 0.71 & 0.132 & \pm 0.013 \\
\hline
\end{tabular}




\section{REFERENCES}

1. J.H. W. Simmons, and W. N. Reynolds. "Dimensional Effects in Graphite on Irradiation," Uranium and Graphite, Inst. Metals Monograph, no. 27, p. 75. 1962.

2. D. R. de Halas, and H. H. Yoshikawa. "Mechanism of Radiation Damage to Graphite at High Temperature," Proceedings of the Fifth Carbon Conference, vol. 1, p. 249. Pergamon Press, London, 1962 .

3. R. E. Nightingale, ed. Nuclear Graphite, chapter 7. Academic Press, 1962.

4. R, E。 Dahl. Measuring and Correlating Neutron Exposure and Damage in Graphite, HW-79793. General Electric Company, Richland, Washington, December 1963.

5. J. T. Meers, and J. F. Doar. High Temperature Radiation Damage to Graphite, Part I., Preparation of Graphites for Irradiation, $H W-80752$. General Electric Company, Richiand, Washington, Apriz 1964.

6. W. C. Morgan. "Foils" A Program for Computing Neutron Exposures from Foil-Activation Data, HW-8136?. General Electric Company, Richland, Washington, Apriz 1964.

7. W. H. Zimmer. The Gamma Analytical System at Redox, RL-SEP-46. General Electric Company, Richland, Washington, Sept. 1964.

8. J. B. Nelson, and D. P. Riley. "The Thermal Expansion of Graphite from $15{ }^{\circ} \mathrm{C}$ to $800^{\circ} \mathrm{C}$ : Part I. Experimental," Proc. Phys. Soc., vol. 57, p. 477 . London, 1945.

9. J.H. Cox. Unpublished data. Pacific Northwest Laboratory, Richland, Washington, Nov. 1966.

10. H. H. Yoshikawa. The Effect of Radiation on Pyrolytic Graphite, HW-78645. General Electric Company, Richland, Washington, January 1964.

11. B. T. Kelley, W. H. Martin, and P. T. Nettley. "Dimensional Changes in Pyrolytic Graphite Under Fast Neutron Irradiation," Phiz. Trans. Roy. Soc. London, Ser. A, vol. 260, pp. 37-49. June 1966 . 


$$
10-20
$$

BNWL -380

12. R. L. Bond, D. H. T. Spencer, and P. A. H. Tee. "The Structure and Reactivity of Pile Graphite," Proceedings of the US/UK Meeting on the Compatibility Problems of Gas-Cooled Reactors, Oak Ridge National Laboratory, February 24-26, 1960, USAEC Report TID-7597, b.k. 1, pp. 374-385. 1961.

13. A. L. Sutton, and V. C. Howard. "The Role of Porosity in the Accommodation of Thermal Expansion in Graphite," J.Nucl. Mater., vol. 7, no. 1, pp. 58-71. 1962.

14. R. J. Price and J. C. Bokros. "Relationship Between Preferred Orientation, Thermal Expansion, and Radiation-Induced Length Changes in Graphite," J.Appl. Phys., vol. 36, no. 6. June 1965 .

15. J.W. Helm. High-Temperature Graphite Irradiations: 800 to $1200{ }^{\circ} \mathrm{C}$, Interim Report No. 1, BNWL-112. Pacific Northwest Laboratory, Richland, Washington, Sept. 1965.

16. J. W. Helm. The $H-4, H-5$ and $H-6$ Irradiation Experiments: Irradiation of $N$-Reactor Graphite, Interim Report No. 1 , HW-81250A. General Electric Company, Richland, Washington, october 1964. 


\section{DISTR I BUT I ON}

Number of

Copies

2

1

7

277

2

2

2

1
AEC Library, Washington

Division of Reactor Development

J. E. Fox

R. Kirkpatrick

AEC Oak Ridge Operations Office

D. F. Cope

AEC Richland Operations Office

C. L. Robinson

R. K. Sharp

Technical Information Library

Division of Reactor Development \& Technology

P. G. Holsted

Division of Technical Information Extension

Douglas United Nuclear, Inc.

P. A. Carlson

A. Russe11

General Atomic Division

G. B。Engle

W. Goedde1

General Electric Company, Richland

R. Cooperstein

M. Lewis

Great Lakes Carbon Corporation

Research and Development Department

Electrode Division

P. O. Box 637, Niagara Fal1s, N. Y.

L. H. Juel

Oak Ridge National Laboratory

W. H. Cook

C. R. Kennedy

Lawrence Radiation Laboratory, Livermore

Dr. James Hadley 


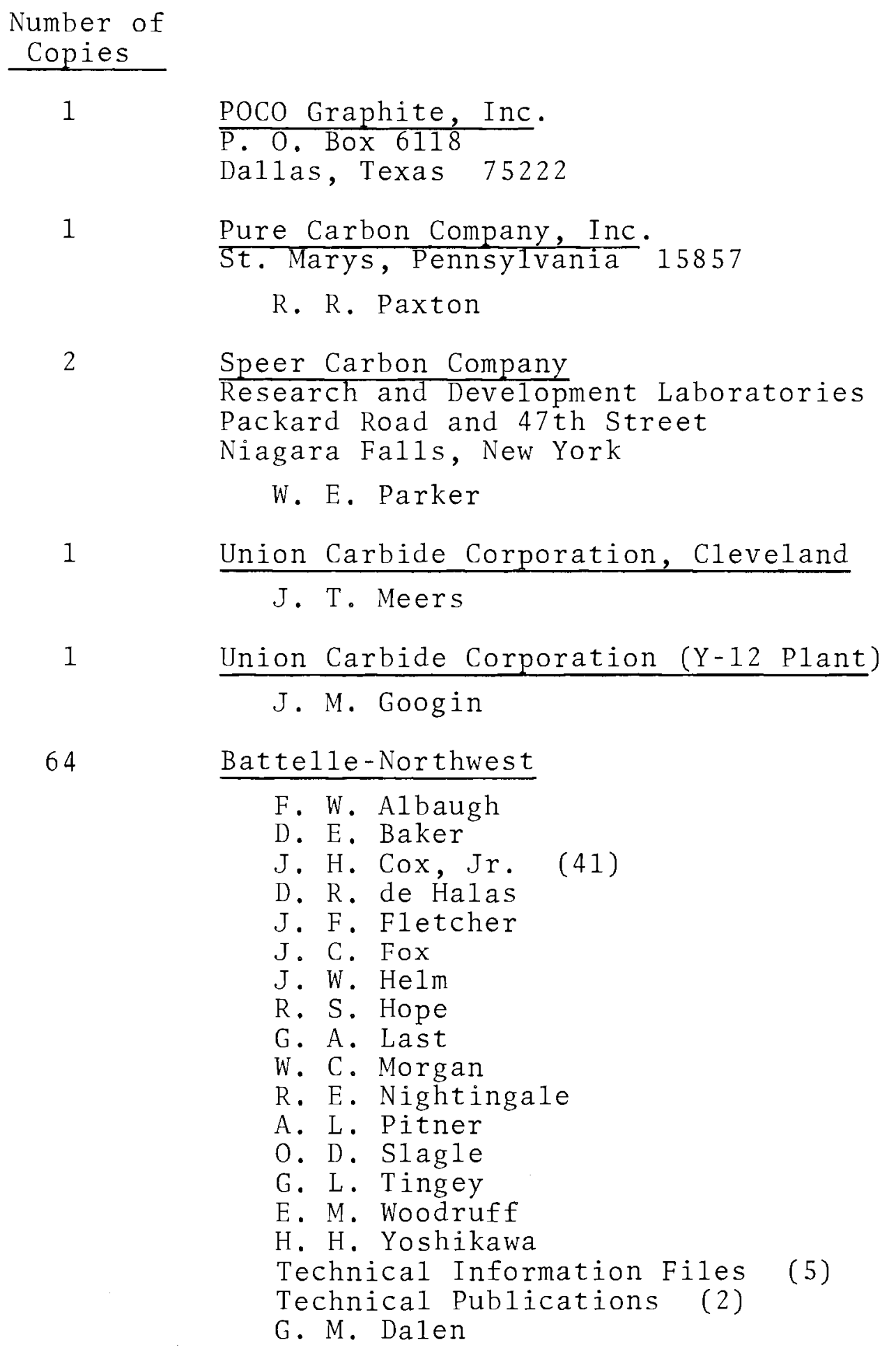

